\title{
The Influence of Symmetrical Feed:Fast Regimes on Oxytetracycline Up- take and Otolith Score in Yellow Perch
}

\author{
Daniel E. Spengler ${ }^{1}$, Travis W. Schaeffer ${ }^{2}$, Casey W. Schoenebeck ${ }^{3}$ and Michael L. Brown ${ }^{*}$ \\ ${ }^{I}$ Pure Fishing, $190018^{\text {th }}$ Street, Spirit Lake, IA 51360, USA \\ ${ }^{2}$ U.S. Geological Survey, Yankton Field Research Station, $31247436^{\text {th }}$, Avenue, Yankton, SD 57078, USA \\ ${ }^{3}$ Department of Biology, University of Nebraska at Kearney, $240111^{\text {th }}$, Avenue, Kearney, NE 68849, USA
}

\begin{abstract}
Periods of growth from symmetric feed:fast regimes (i.e., days fed followed by the same number of days fasted) may increase the uptake of oxytetracycline $\left(\mathrm{C}_{22} \mathrm{H}_{24} \mathrm{~N}_{2} \mathrm{O}_{9} \cdot \mathrm{HCL}[\mathrm{OTC}]\right)$ compounds in fishes; however, little empirical data exists. Therefore, we experimentally determined if such feeding regimes influenced the concentration of OTC incorporated in muscle and skeletal (e.g., otoliths) tissues. Individually-reared female and batch-reared (male and female), age-1 yellow perch Perca flavescens were subjected to one of four experimental feeding regimes: control (i.e., fed daily), $\mathrm{D} 2$ (i.e., $2 \mathrm{~d}$ feed, $2 \mathrm{~d}$ deprivation), D6, or D12 symmetrical feed:fast regimes. Following several feeding cycles on these feeding regimes, fish were submersed in a $600 \mathrm{mg} / \mathrm{L}$ buffered OTC solution; otoliths and muscle tissue were excised and processed to determine OTC uptake via mark quality and concentrations. Ranked otolith scores (mark quality) were significantly lower for the D2 feeding regime than control, D6, and D12 scores for both individual and batch trials suggesting that frequent food deprivation restricts osteogenesis, while daily or extended feeding periods contribute to osteogenesis. In batch-reared fish, total OTC and 4-epioxytetracycline peak concentrations in muscle tissue did not significantly differ among treatments but were significantly greater for smaller individuals within treatments suggesting that the OTC uptake and elimination response is mechanistically related to higher gill ventilation volume and gastric ingestion rate of small fish providing increased chemical assimilation and decreased clearing time following OTC immersions. Increased otolith mark quality derived from such feeding protocols may be of particular interest to fisheries managers conducting stock contribution assessments of yellow perch, but this induction strategy may apply to other species as well as therapies for hatchery stocks.
\end{abstract}

Keywords: Mark quality, muscle tissue, otolith, oxytetracycline, symmetrical feed:fast regime, yellow perch

\section{INTRODUCTION}

Supplemental stockings are often used by fisheries managers to enhance a weak year class [1]. For example, supplemental stockings have been used on yellow perch Perca flavescens populations that display erratic population dynamics and population-dependent recruitment patterns to enhance angling opportunities [2]. One difficulty that arises from such stockings is the inability of fisheries managers to differentiate between stocked and naturally produced fish [3, 4]. To address this problem, a series of studies have looked at mark efficacy in skeletal structures after immersing juvenile yellow perch in oxytetracycline hydrochloride (OTC) solutions $[2,4,5]$. Mark quality and detection is contingent upon OTC solution concentration, immersion duration, water chemistry, and fish size $[4,5]$. However, other techniques may improve the utility of marking agents by increasing chemical uptake in fishes. One such approach may be to in

*Address correspondence to this author at the Department of Natural Resource Management, South Dakota State University, Box 2140B, Northern Plains Biostress Laboratory, Brookings, SD 57007, USA;

Tel: (605)688-6121; Fax: (605)688-4515;

E-mail: michael.brown@sdstate.edu fluence fish growth rate through feed:fast cycles, as done in compensatory growth (CG) experiments [6-8].

To test the hypothesis that feed:fast regimes induce varied OTC uptake, we subjected yellow perch to different symmetrical feed:fast regimes (i.e., days fed followed by the same number of days fasted) to determine whether feeding history and subsequent uptake of OTC into somatic tissue and otolith mark quality differed in yellow perch. In addition, OTC marking of fishes has primarily been conducted for larval and juvenile stages [9]; more information is needed for fishes in the advanced life stages. Therefore, the following objectives were investigated for age-1 yellow perch reared under differing feed:fast regimes: 1) determine the relationship between growth on different feed:fast regimes and otolith mark quality in individually-reared, female yellow perch, 2) quantify concentrations of OTC integrated into muscle tissue and subsequent otolith mark quality in batchreared yellow perch, and 3) determine if advanced, juvenile yellow perch can be successfully marked with OTC immersion following feed:fast cycles.

\section{MATERIALS AND METHODOLOGY}

Yellow perch were collected from a single cohort previously stocked in a $0.028 \mathrm{~km}^{2}$ natural wetland in Day County, 
South Dakota, USA, using four small-scale, modified fyke nets $(0.64 \mathrm{~cm}$ mesh). Fish were transferred to South Dakota State University, Brookings, South Dakota, USA, where they were feed trained and allowed to condition for $35 \mathrm{~d}$ in $681 \mathrm{~L}$ tanks attached to a recirculating aquaculture system. Yellow perch were sorted into one of two groups for two separate trials, with the largest individuals (assumed to be females; later verified by necropsy inspection) allocated to individual tanks for controlled rearing and marking; hereafter referred to as the individual trial. Smaller individuals were allocated to large circular tanks for a practical batch rearing trial; hereafter referred to as the batch trial.

Individual trial. Twenty-four yellow perch (initial weight $=51.9 \pm 0.9 \mathrm{~g}[$ mean $\pm \mathrm{SE}])$ were randomly selected and individually stocked in one of 24, 110-L insulated tanks. Fish were randomly assigned to either one of three treatments or a control, providing six replicate tanks each. Treatments were based on 2:2, 6:6, or 12:12 d feed:fast regimens (hereafter referred to as D2, D6, and D12, respectively), while fish on the control regimen were fed to satiation daily. Three fish from the original 24 were not included in analyses for the following reasons. First, a mortality occurred after OTC immersion but prior to completion of the additional growth period. Second, studies have shown sexually dimorphic growth in yellow perch where females grow faster than males [10-12]; therefore, two male fish were removed providing only female fish for analyses. Such selection was warranted to reduce any bias in growth results, and therefore, potential OTC uptake from potentially uneven sex ratios among treatments.

A biological filtration system, connected to a recirculating water supply, was used to ensure similar water quality across treatments. Each tank was supplied with recirculated water at an approximate rate of $0.7 \mathrm{~L} / \mathrm{min}$. Water temperatures in tanks ranged from 20.9 to $21.5^{\circ} \mathrm{C}$ with a mean of $21.1 \pm 0.05^{\circ} \mathrm{C}$. A photoperiod of $14: 10 \mathrm{~h}$ light:dark was maintained throughout the experiment.

All fish were fed rations of fathead minnows Pimephales promelas to satiation twice daily (0800-1000 and 1600-1800 h) during the feeding portion of each cycle. At the start of a feeding cycle, three minnows were supplied to each tank; additional minnows were added until satiation was achieved and three minnows remained in each tank. Throughout the feeding cycle, we ensured that three minnows remained in each tank after every feeding. Any minnows remaining within a treatment tank at the end of a feeding period were removed prior to starting the fasting cycle. To quantify cumulative food consumption, we monitored the number of minnows consumed on a daily basis, and summed the amounts for each fish. Dead or regurgitated minnows were removed, replaced, and not considered in consumption estimates. Cumulative food consumption ( $\mathrm{g}$ wet weight of minnows) was determined as the product of the number of minnows eaten times the mean live weight of prey. To reduce variability of prey size, all fathead minnows $(1.28 \pm 0.08 \mathrm{~g})$ were first graded (commercial grade 18) for size uniformity and then subsamples weighed to determine mean prey weight.

Weights of yellow perch $( \pm 0.1 \mathrm{~g})$ were recorded on the following schedule to monitor growth and perform visual health assessments of fish: prior to feeding periods for $2 \mathrm{D}$ fish, prior to and directly after feeding periods for 6D fish, prior to and in the middle of feed and fast periods for 12D fish, and every $6 \mathrm{~d}$ for control fish. Fish weights were determined as follows: each fish was netted and blotted to remove excess water, transferred to a tared, water-filled (from tanks) container, and weighed. Absolute growth rates (AGR) of individuals were determined as;

$$
A G R=\frac{\left(W_{f}-W_{i}\right)}{T_{t}}
$$

where $\mathrm{W}_{\mathrm{f}}$ and $\mathrm{W}_{\mathrm{i}}$ were the final and initial live weights $(\mathrm{g})$, respectively, and $T_{t}$ is the total number of days, including both feeding and fasting days. Total consumption (TCR) and modified consumption rates (MCR) were also calculated for each fish as:

$$
T C R=\frac{C}{T_{t}} \text { and } M C R=\frac{C}{T_{f}}
$$

where $\mathrm{C}$ is cumulative food consumption $(\mathrm{g})$, and $\mathrm{T}_{\mathrm{f}}$ is the number of days fed not including any fasting days. Gross growth efficiency (GGE) was determined for each fish as;

$$
G G E=\frac{\left(W_{f}-W_{i}\right)}{C}
$$

Batch trial. Four groups of fifty, age-1yellow perch (initial weight $=30.2 \pm 1.12 \mathrm{~g}$ ) were placed in four unreplicated (due to the limited number of fish available), $681 \mathrm{~L}$ tanks and randomly assigned to either a control, D2, D6, or D12 feed:fast regime. A separate biological filtration system from the individual trial, connected to a recirculating water supply, was used to ensure similar water quality across treatments. Each tank was supplied with recirculated water at an approximate rate of $3.3 \mathrm{~L} / \mathrm{min}$. Water temperatures in tanks ranged from 19.7 to $20.1^{\circ} \mathrm{C}$ with a mean of $19.9 \pm 0.03^{\circ} \mathrm{C}$. A photoperiod of 14:10 h light:dark was maintained throughout the experiment. Six total mortalities occurred throughout the duration of the experiment in the following treatments: 4 in control, 1 in D2, 1 in D12.

Fish were fed 1:1 rations of 2.5 and $4.5 \mathrm{~mm}$ Silver Cup Steelhead Extruded Floating Feed (Nelson and Sons, Inc., Murray, Utah) to satiation. A subsample of 150 pellets for both sizes was taken and weighed to determine an estimated mean mass per pellet. To quantify cumulative food consumption, we monitored the amount of feed offered to each tank on a daily basis; on the following day, prior to the next feeding, all uneaten pellets were removed, separated by size, and counted to estimate the amount of uneaten feed. Cumulative food consumption ( $\mathrm{g}$ dry feed) was determined as the product of the number of uneaten pellets multiplied by the mean mass per pellet for each size then subtracted from the total food mass fed. Feeding occurred twice daily, at 0800 1000 and 1600-1800 hours. Feeding trial duration, prior to OTC immersions, for both studies consisted of 18,7 , and 4 feed:fast complete cycles for the D2, D6, and D12 treatments, respectively.

Total tank weights of yellow perch $( \pm 1 \mathrm{~g})$ were sampled on the same schedule and for the same reasons as the indi- 
vidual trial fish. Total tank weights were determined as follows: a subsample of 20 fish from one tank was netted and briefly suspended in the air to remove excess water, transferred to a tared, water-filled (from tanks) container, and weighed. Similar to the individual trial, AGR, TCR, MCR, and GGE were calculated for each tank in the batch trial; however, no statistical analyses were performed due to unreplicated treatments.

OTC immersions. Due to the offsetting nature of the feeding and weighing cycles and to maintain any physiological characteristics (i.e., fluctuating metabolic rates, etc.) that may be associated with the feed:fast regimes, all treatments received OTC immersions the day after completing a feeding period. After a feeding cycle was terminated, each tanks received a $600 \mathrm{mg} / \mathrm{L}$ OTC hydrochloride $\left(\mathrm{C}_{22} \mathrm{H}_{24} \mathrm{~N}_{2} \mathrm{O}_{9}{ } \mathrm{HCL}\right)$ solution for six hours, similar to methods used in another study [5] that looked at the parameters of mark detection and tissue residue depletion. Oxytetracycline solutions were buffered to neutral $\mathrm{pH}$ with sodium phosphate dibasic $\left(\mathrm{Na}_{2} \mathrm{HPO}_{4}\right)$ [5]. Additionally, an antifoam agent (5\% silicone base, food grade) was used to minimize the foaming of OTC solutions under aeration. During immersion, dissolved oxygen and $\mathrm{pH}$ were monitored every hour using an YSI model 6820-C-M multi-parameter water quality meter (YSI Incorporate, Yellow Springs, Ohio). After the immersion period was terminated, OTC solutions were flushed from the treatment tanks and water recirculation was re-established.

In the batch trial, three large (153 to $191 \mathrm{~mm}$ ) and three small (110 to $145 \mathrm{~mm}$ ) fish were randomly selected from each treatment $13.5 \mathrm{~h}$ post-immersion. Fish were euthanized with $200 \mathrm{mg} / \mathrm{L}$ tricaine methanesulfonate (MS-222) and somatic tissue (fillets, no bones or skin) was excised and archived at $-20^{\circ} \mathrm{C}$ pending analysis. High-pressure liquid chromatography (HPLC) was used to quantify both uptake and breakdown (4-epioxytetracycline peaks [Epi-OTC]) of OTC in somatic tissue; quantitation level for fish tissue was $0.05 \mu \mathrm{g} \mathrm{OTC/g} \mathrm{[13].} \mathrm{Total} \mathrm{OTC} \mathrm{and} \mathrm{Epi-OTC} \mathrm{concentra-}$ tions $(\mathrm{mg} / \mathrm{L})$ from the HPLC analysis were standardized by individual body weights $(\mathrm{g})$. All fish in the batch trial not sacrificed for HPLC were fed daily rations until satiation for an additional $40 \mathrm{~d}$ of growth to separate the OTC-induced mark from the margin of the otolith.

Following the additional growth period, five fish from three size categories $($ small $=<155 \mathrm{~mm}$; medium $=160$ to $175 \mathrm{~mm}$; large $=>185 \mathrm{~mm}$ ) in the batch trial were selected from each treatment for otolith extraction. In addition to the batch-marked fish, otoliths excised from the individualreared fish, determined to be females following necropsy, were used in mark quality analyses. Prior to otolith extraction, all fish were euthanized with MS-222 (150 ppm). All otoliths were cleaned and temporarily stored in darkness to prevent photo degradation of fluorescent marks.

Otoliths from both trials were analyzed using a Nikon E400 compound microscope with a $100-\mathrm{W}$ ultraviolet $(\mathrm{Hg}$ arc) light and fluorescent detection accessories (B3 filter cube, $505-\mathrm{nm}$ dichroic mirror, 420 to $490-\mathrm{nm}$ excitation filter, and 520 IF barrier filter). Otoliths (unsanded) were scored by two readers following the procedures of a different study [5], where two readers independently scored mark quality (i.e., presence and mark intensity) from 0 to $3(0=$ no mark; 1 = barely detectable; 2 = easily detected, but partial mark or mark was not brilliant; and 3 = bright, well-defined, continuous mark). A third reader was included when score discrepancies occurred between readers one and two.

Statistical analysis. Absolute growth rates, TCR, MCR, and GGE for individual trial fish were analyzed among treatments using a one-way analysis of variance (ANOVA). If significant treatment effects were detected, a post-hoc Tukey's test was used to determine where differences occurred among treatment means. Wilcoxon Signed Rank tests were used to determine whether significant differences occurred in otolith scores between primary readers. When no significant differences occurred between primary readers, two-way ANOVA or Kruskal-Wallis (if assumptions for normality failed) tests were used to determine if differences in otolith scores occurred among treatments or length categories; post hoc Tukey's test or multiple Mann-Whitney U tests were employed if statistical differences occurred. Additionally, otolith score agreement between readers one and two was analyzed with Spearman's rank correlation. High pressure liquid chromatography results for total OTC and EpiOTC peak values from somatic tissue were evaluated among treatments and length categories with two-way ANOVA. Systat (version 11) and SigmaPlot (version 12.0) software (SPSS Inc., Chicago, Illinois) were used for all analyses with $\alpha=0.05$.

\section{RESULTS AND DISCUSSION}

Growth and consumption rates of both trials. Absolute growth rates of fish in the individual trial indicated that D2 fish had significantly lower $(F=3.76 ; \mathrm{df}=3 ; P=0.03)$ growth results than D12 fish (Table 1). Similarly, TCR indicated that $\mathrm{D} 2$ consumed significantly less $(F=3.41 ; \mathrm{df}=3$; $P=0.04$ ) biomass of minnows than D6 fish; however, when compared with MCR, D2 fish were not significantly different from any other treatment, while the control fish consumed significantly less $(F=7.60 ; \mathrm{df}=3 ; P<0.01)$ than D6 and D12 (Table 1). Gross growth efficiencies were not statistically different $(F=2.30$; df $=3 ; P=0.11)$ among treatments (Table 1). While no statistical analyses could be performed on batch trial fish, AGR and GGE did indicate similar trends seen in the individual trial fish. Total consumption rates for control fish were almost twice the rate of any other treatment, while MCR showed a deceasing trend as fasting length increased (Table 1).

Differences in growth and consumption rates may have resulted from several factors. First, longer fasting periods may have increased overall consumption; thereby, resulting in increased somatic growth. This becomes apparent when looking at AGR and TCR in the individual fish; growth and consumption of D12 and D6 fish, respectively, was almost double that of D2 fish. Some of this difference may have occurred due to additional stress on D2 fish from increased handling time from more weighing periods. Second, variation in food availability has been suggested to play a significant role in regulating the metabolic function of fishes with lower metabolic rates increasing the scope of growth in fish prior to a feeding cycle $[6,14,15]$. Therefore, D2 fish may have not had adequate time to lower their metabolic rates as compared to D6 and D12; thereby, limiting their overall scope of growth during the feeding period. 
Table 1. Final number of fish per treatment (n), absolute growth rate (AGR), total consumption rate (TCR), modified consumption rate (MCR), and gross growth efficiency (GGE) of individually-reared female and batch-reared yellow perch on control and experimental feeding regimens. Treatment groups D2, D6, and D12 were distinguished by symmetric feed:fast cycles of 2:2, 6:6, and 12:12 d, respectively; the control treatment group received rations daily. Values [means (SE)] not significantly different (P $\geq 0.05$ ) have the same letter for a given dependent variable; no statistical analyses performed for batch trial treatments.

\begin{tabular}{|c|c|c|c|c|c|}
\hline Group & $n$ & $\operatorname{AGR}^{a}(g / d)$ & $\operatorname{TCR}^{\mathrm{b}}(\mathrm{g} / \mathrm{d})$ & $\operatorname{MCR}^{c}(g / d)$ & GGE $^{\mathrm{d}}$ \\
\hline \multicolumn{6}{|c|}{$\underline{\text { Individual }}$} \\
\hline D2 & 5 & $0.17(0.04) \mathrm{b}$ & $1.4(0.12) \mathrm{b}$ & $2.8(0.23) \mathrm{ab}$ & $0.12(0.01) \mathrm{a}$ \\
\hline D6 & 6 & $0.33(0.15) \mathrm{ab}$ & $2.1(0.22) \mathrm{a}$ & $3.6(0.38) \mathrm{a}$ & $0.15(0.02) \mathrm{a}$ \\
\hline \multicolumn{6}{|c|}{ Batch } \\
\hline Control & 46 & 15.9 & 20.9 & 21.6 & 0.69 \\
\hline D2 & 49 & 4.3 & 10.4 & 20.4 & 0.42 \\
\hline D6 & 50 & 8.1 & 10.6 & 18.2 & 0.76 \\
\hline
\end{tabular}

${ }^{a} \mathrm{AGR}=($ final weight $[\mathrm{g}]-$ initial weight $[\mathrm{g}]) /$ total number of days [i.e., feed and fast $\left.\mathrm{d}\right]$

${ }^{\mathrm{b}} \mathrm{TCR}=$ cumulative food consumption $[\mathrm{g}] /$ total number of days [i.e., feed and fast $\mathrm{d}$ ]

${ }^{\mathrm{c}} \mathrm{MCR}=$ cumulative food consumption [g] / total number of days fed [i.e., feed d only]

${ }^{\mathrm{d}} \mathrm{GGE}=($ final weight $[\mathrm{g}]-$ initial weight $[\mathrm{g}]) /$ cumulative food consumption $[\mathrm{g}]$

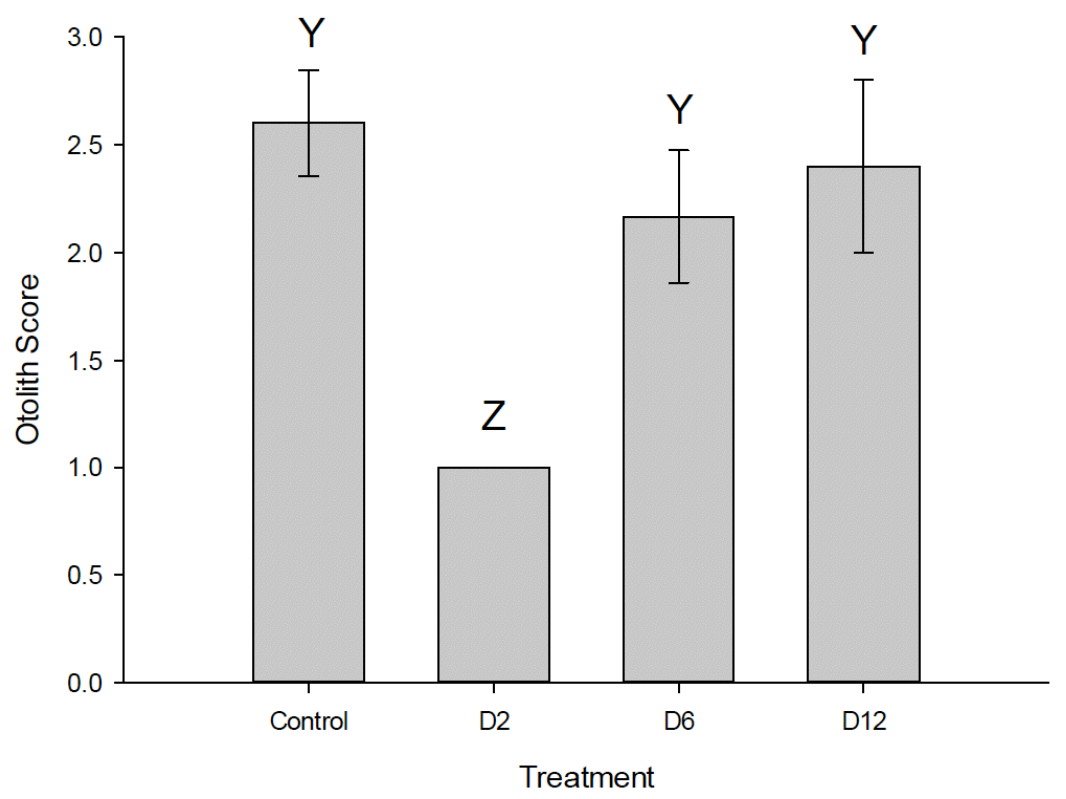

Fig. (1). Otolith scores (mean $\pm \mathrm{SE}$ ) for individually-reared female yellow perch subjected to control, D2, D6, and D12 feeding regimes. Treatment groups D2, D6, and D12 were distinguished by symmetric feed:fast cycles of 2:2, 6:6, and 12:12 d, respectively; the control treatment received rations daily. Values considered not different $(P \geq 0.05)$ if followed by same letter.

Mark quality in individually-reared fish. Detection of OTC marks on the otoliths $(n=21)$ of female yellow perch from the individual trial was $100 \%$. Similarly, other studies evaluating otolith mark efficacy in yellow perch have reported detection rates of $100 \%[4,5]$. Otolith mark quality (scores) did not significantly differ between the two primary readers $(Z=-1.00 ; \mathrm{df}=20 ; P=0.32)$. Agreement $(r=0.88$; $P<0.01)$ between the two primary readers was high. Other studies using similar protocols for scoring marked otoliths of other fish species have been less successful [16].
Otolith scores significantly differed among treatments (including controls) $(F=6.05 ; \mathrm{df}=20 ; P=0.01)$ for fish in the individual trial with D2 fish experiencing lower otolith mark quality (Fig. 1). Several factors may have contributed to the lower otolith scores for the D2 treatment relative to the control, D6, and D12 treatments. First, a similar response was detected in both individual and batch experiments suggesting that frequent food deprivation restricts osteogenesis, while daily or extended feeding periods contributes to osteogenesis. Second, one study [17] found that manipulating 

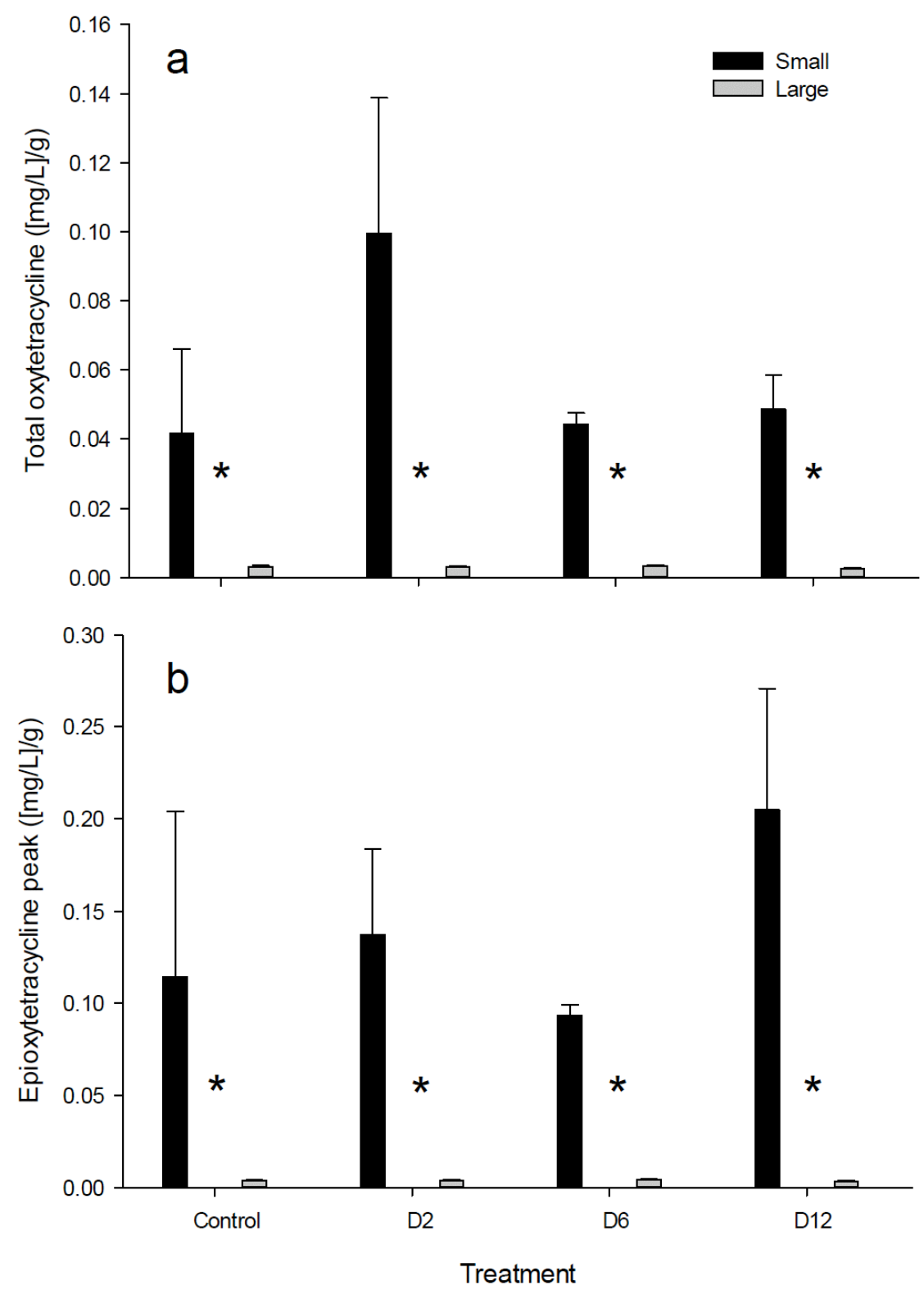

Fig. (2). (a) Total OTC concentration (mean \pm SE) and (b) epioxytetracycline (Epi-OTC) peak concentration for somatic tissue in small (110 to $145 \mathrm{~mm}$ ) and large (153 to $191 \mathrm{~mm}$ ) batch-reared yellow perch collected from the control, D2, D6, and D12 feeding regimes $13.5 \mathrm{~h}$ postOTC immersion. Treatment groups D2, D6, and D12 were distinguished by symmetric feed:fast cycles of 2:2, 6:6, and 12:12 d, respectively; the control treatment received rations daily. Mean total OTC and EPI-OTC peak concentration values within size categories among treatments were not significantly different $(\mathrm{P} \geq 0.05)$; an asterisk $\left(^{*}\right)$ indicates a significant difference in mean total OTC concentration between size categories within treatments.

food rations (i.e., deprivation, low, and high food rations) influenced otolith growth in juvenile King George whiting Sillaginodes punctata at standardized temperatures. Specifically, higher food rations yielded more otolith growth relative to low food rations and deprivation. If otolith growth is influenced by manipulating feed rations, otolith growth in this study may have also been influenced by treatmentspecific durations of feed:fast cycles. In a sister study, hyperphagic responses (i.e., when food consumption rates are significantly higher than those of fish not experiencing depressed growth [15]) in fish held on symmetrical 6:6 and $12: 12 \mathrm{~d}$ feed:fast cycles were considerably longer than those observed in fish on the 2:2 d cycles [18]; therefore, it is possible that increased periods of somatic growth of these two groups during feeding cycles, due to increased consumption rates, may have increased osteogenesis. Hence, increased rates of osteogenesis may have influenced the amount of OTC integrated into the otoliths of the control, D6, and D12 fish, subsequently influencing otolith mark quality.

Muscle tissue OTC concentrations in batch-reared fish. In the batch trial, yellow perch were held in mixed-sex groups, allowing us to conduct immersions on a scale similar to a practical hatchery application. Muscle tissue OTC concentrations indicated that chemical uptake was significantly greater for the smaller length category $(F=20.79$; df $=1,14$; $P<0.01)$ but did not differ among treatments $(F=1.37$; df $=3,14 ; P=0.29$ ) (Fig. 2a). Similarly, Epi-OTC peaks were 


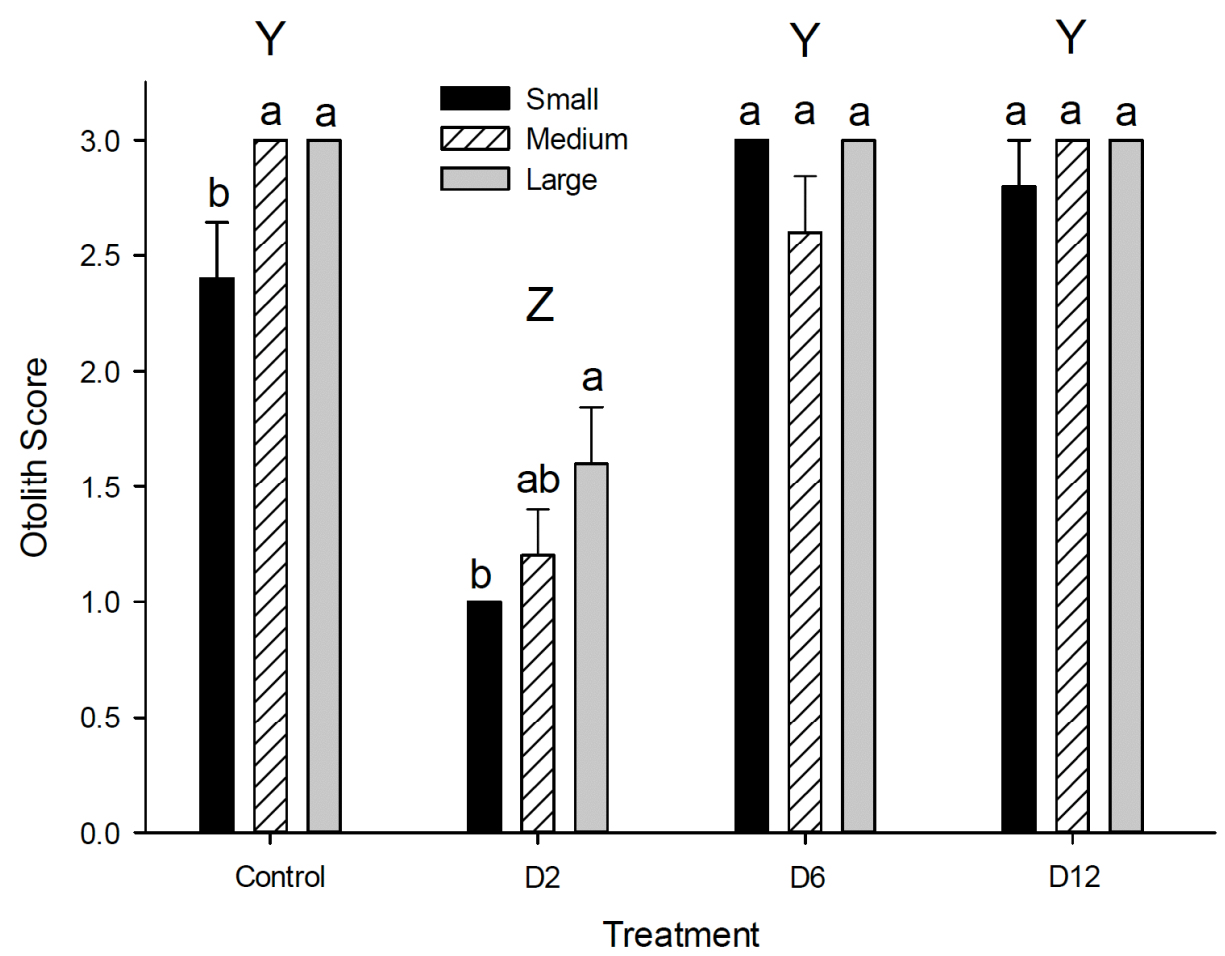

Fig. (3). Otolith score (mean $\pm \mathrm{SE}$ ) for batch-reared yellow perch subjected to control, D2, D6, or D12 feeding regimes. Treatment groups D2, D6, and D12 were distinguished by symmetric feed:fast cycles of 2:2, 6:6, and 12:12 d, respectively; the control treatment received rations daily.Length categories are defined as small $(\mathrm{S}=<155 \mathrm{~mm})$, medium $(\mathrm{M}=160$ to $175 \mathrm{~mm})$, and large $(\mathrm{L}=>185 \mathrm{~mm})$. Values among treatments and length categories considered not different $(\mathrm{P} \geq 0.05)$ if followed by same letter.

significantly greater for the smaller length category $(F=$ 24.26; $\mathrm{df}=1,14 ; P<0.01)$ but did not differ among treatments $(F=0.81$; df $=3,14 ; P=0.51)$ (Fig. 2b). These results suggest that different symmetrical feed:fast regimes may not regulate the uptake of OTC in somatic tissue, but rather uptake and depletion of OTC may be better related to fish size. Smaller fish assimilated and depleted OTC faster than larger fish within treatments. We suggest that the OTC uptake and elimination response is mechanistically related to the higher gill ventilation volume and gastric ingestion rate of small fish; thereby, providing increased chemical assimilation and decreased clearing time following OTC immersion. This size relationship, however, did not appear to influence otolith scores within treatments (i.e., no differences among small, medium, or large size categories; Fig. 3). This suggests that otolith mark quality may be related to growth and potential hyperphagic responses associated with symmetrical feed:fast cycles. In a sister study, higher estimated growth trajectories and longer hyperphagic periods were seen in fish held on symmetrical 6:6 and 12:12 d feed:fast cycles compared to those on 2:2 d cycles [18]. Therefore, increased growth rates and extended hyperphagic responses may allow OTC to incorporate into the tissues quicker, providing more OTC to be incorporated into skeletal structures.

Otolith mark quality in batch-reared fish. A total of 60 otoliths ( $n=15$ fish per treatment) were subjected to microscopic interpretation. Mark detection was similar to the individual trial $(100 \%)$, and mean scores did not significantly differ $(Z=0.58 ; \mathrm{df}=59 ; P=0.75)$; agreement on otolith scores between readers was also highly correlated $(r=0.93$; $P<0.01)$. The interaction describing mean otolith score among treatments was significant as otolith scores were lower for the $\mathrm{D} 2$ treatment $(\mathrm{F}=2.410 ; \mathrm{df}=6,59 ; \mathrm{P}=0.041$, Fig. 3). Similarly, otolith scores were size dependent in the control treatment with fish in the small category having significantly lower scores than the medium $(\mathrm{q}=1.359 ; \mathrm{df}=$ $1 ; \mathrm{P}=0.016)$ and large $(\mathrm{q}=1.359 ; \mathrm{df}=1 ; \mathrm{P}=0.016)$ categories and D2 treatment with fish in the small category having significantly lower scores than the large category $(q=1.359$; $\mathrm{df}=1 ; \mathrm{P}=0.016$, Fig. 3). However, size-dependent scores were not observed in the D6 or D12 treatments.

\section{CONCLUSION}

Understanding how feeding protocols influence chemical uptake and otolith mark quality in fishes is beneficial, particularly when choosing feeding protocols that produce high quality OTC otolith marks in hatchery-reared fishes used for stocking assessments. Due to the poor mark quality observed in the D2 treatment, short duration symmetrical feed:fast regimes should be excluded from future investigations because low-quality otolith marks are not advantageous to stock contribution studies.

From a logistic standpoint, the symmetrical feed:fast procedures used in this study may be appealing to hatcheries, as the time spent feeding fish and maintaining tanks was significantly reduced during deprivation periods. Prolonged experiments, however, may not accommodate all production schedules. Therefore, we recommend future studies investigate feeding schedules (i.e., $<72 \mathrm{~d}$ ) to determine if shorter experiments can produce similar mark quality. If successful, shorter feeding schedules would reduce the holding period. The results from these experiments suggest that feed ma- 
nipulation can influence otolith mark quality in fishes and that advanced juvenile yellow perch can be efficiently marked with OTC following feed:fast cycles.

\section{CONFLICT OF INTEREST}

The authors confirm that this article content has no conflicts of interest.

\section{ACKNOWLEDGEMENTS}

We would like to thank Dr. Steven R. Chipps, Steven Ranney, and the late Dr. Robert Klumb for their assistance with equipment, procedures, and measurements. Additionally, we would like to thank Dr. Mark Kaemingk for his friendly review of this manuscript. Funding for this project was provided by South Dakota Department of Game, Fish and Parks through Federal Aid in Sport Fish Restoration Project F-15-R, study 1504.

\section{REFERENCES}

[1] Heidinger RC. Stocking for sport fisheries enhancement. In: Kohler CC, Hubert WA, Eds. Inland Fisheries Management in North America, $2^{\text {nd }}$ ed. Bethesda: Am Fisheries Soc 1999; pp. 375-402.

[2] Brown ML, St Sauver T. An assessment of yellow perch, Perca flavescens, stocking contributions in eastern South Dakota lakes. Fish Manag Ecol 2002; 9: 225-234.

[3] Schumann DA, Koupal KD, Hoback WW, et al. Evaluation of sprayed fluorescent pigment as a method to mass-mark fish species. Open Fish Sci J 2013; 6: 41-47.

[4] Unkenholz EG, Brown ML, Pope KL. Oxytetracycline marking efficacy for yellow perch fingerlings and temporal assays of tissue residues. Prog Fish Cult 1997; 59: 280-284.

[5] Brown ML, Powell JL, Lucchesi DO. In-transit oxytetracycline marking, nonlethal mark detection, and tissue residue depletion in yellow perch. N Am J Fish Manag 2002; 22: 236-42.

[6] Mehner T, Wieser W. Energetics and metabolic correlates of starvation in juvenile perch (Perca fluviatilis). J Fish Biol 1994; 45: 325-333.
[7] Hayward RS, Noltie DB, Wang N. Use of compensatory growth to double hybrid sunfish growth rates. Trans Am Fish Soc 1997; 126: 316-322.

[8] Hayward RS, Wang N. Failure to induce over-compensation of growth in maturing yellow perch. J Fish Biol 2001; 59: 129-140.

[9] Bowden BC. Pharmacokinetic profiles of oxytetracycline in yellow perch (Perca flavescens) as determined by plasma concentration following different routes of administration. MSc/MA thesis. Blacksburg (VA); Virginia-Maryland Regional College of Veterinary Medicine 2001

[10] Malison JA, Kayes TB, Best CD, et al. Sexual differentiation and use of hormones to control sex in yellow perch (Perca flavescens). Can J Fish Aquat Sci 1986; 43: 26-35.

[11] Malison JA, Kayes TB, Wentworth BC, et al. Growth and feeding responses of male versus female yellow perch (Perca flavescens) treated with estradiol-17ß. Can J Fish Aquat Sci 1988; 45: 1942 1948.

[12] Uphoff CS, Schoenebeck CW. Quantifying inter-population variability in yellow perch sexual size dimorphism. J Fresh Ecol 2012; 27: 507-516.

[13] Houglum JE, Larson RD. Liquid chromatographic determination of oxytetracycline residue in fish tissue and in water. Washington DC; US Department of Health and Human Services Laboratory 1999; Information Bulletin 15(3): p. 4180.

[14] Wieser W, Krumschnabel G, Ojwang-Okwor JP. The energetics of starvation and growth after refeeding in juveniles of three cyprinid species. Environ Biol Fish 1992; 33: 63-71.

[15] Ali M, Nicieza A, Wootton RG. Compensatory growth in fishes: a response to growth depression. Fish Fish 2003; 4: 147-90.

[16] Hawkins MJ. Use of high pressure liquid chromatography to detect and quantify oxytetracycline marks in walleye otoliths and dorsal spines. MSc/MA thesis. Brookings (SD); South Dakota State University 2002.

[17] Barber MC, Jenkins GP. Differential effects of food and temperature lead to decoupling of short-term otolith and somatic growth rates in juvenile King George whiting. J Fish Biol 2001; 58: 13201330 .

[18] Schaeffer TW, Spengler DE, Schoenebeck CW, et al. Effect of feeding-fasting cycles on oxygen consumption and bioenergetics of female yellow perch. Trans Am Fish Soc 2012; 141: 1480-1491.

This is an open access article licensed under the terms of the Creative Commons Attribution Non-Commercial License (http://creativecommons.org/licenses/ by-nc/3.0/) which permits unrestricted, non-commercial use, distribution and reproduction in any medium, provided the work is properly cited. 